\title{
Active asset management: Practicalities and realities. Does it really exist? Does it enhance returns? What does it do for risk profiles?
}

Recerved. 8 July 2005

\section{Nick Jacobs}

is managing director and founder of Rowan Asset Management (RAM). Before creating RAM, Nick's property career spanned work as a chartered surveyor plus positions at Waterglade plc, AMEC and Lloyds TSB's Property Division.

\begin{abstract}
Active asset management is a skill that managers of commercial property portfolios often claim they offer their clients - but are their claims to 'manage actively' accurate and trustworthy? This paper sets out, comprehensively, the field of operation any genuine active asset manager should cover - from valueadding management of landlord-tenant relationships to the analysis of latent values, debt and gearing management and liaison with local town planners. The correct organisation and systems that drive property investment cashflows to add investor value are also set out. Backed by up-to-date financial data the paper also provides an overview that includes both micro and macro perspectives: the UK's current economic status is viewed in tandem with retail property performance plus expert predictions. The reader is informed how active asset management lowers investment risk at a time when bank lending to commercial property is said by some commentators to be disproportionately high. Property is an illiquid and complex investment medium; the paper attempts to show a way forward when retail and leisure property are threatened by a downturn in consumer spending.
\end{abstract}

\section{Keywords:}

active asset management, risk, fees, incentives, investor returns, interest rates, IT, leases, debt, gearing, loan documentation

Nick Jacobs Rowan Asset Management 1a Avery Row London W1K $4 \mathrm{AJ}$, UK Tel: +44 (o) 2074997880 Fax: +44 (o) 2074084880 E-maıl: nj@rowanasset.co.uk Website: www.rowanasset.co.uk

\section{INTRODUCTION}

On London's Oxford Street the often-heard mantra is 'Hare hare hare Krishna'. A few hundred yards south in Berkeley Square on a quiet day one can hear the property companies softly issuing their own words of inspiration: 'Active active active asset management'. 
Value of asset management

Existence of active asset management
Mere words of fashion, or a reflection of a deep-seated philosophy practised in daily business life? What do the words 'active asset management' mean - and what are the implications for lenders and investors in the dynamic world of commercial property?

Lenders are frequently assailed by income-producing property companies brandishing the 'active management' slogan - the companies use it like a talisman or 'open sesame' when they approach banks, pension and insurance institutions and potential co-investors.

The audience, both banks and investors, may have become jaundiced by too many promises and meaningless repetition. Yet there is a value in the true practice of asset management: it has become even more relevant in times of closing margins between cost of borrowing and yields on income-producing property.

The main source of liquidity in the property market and provider of volume is bank lending. So one can try to analyse this important functionary's requirements.

The key criteria of a typical lender are:

- predictability

- track record

- interest cover

- amortisation and repayment over a set period

- margin over cost of money

- fees on placing of business

- straightforwardly presented propositions

- opportunity for repeat business.

This list is far from exhaustive, but it would be surprising if the elements were not within the top ten of most lenders' key criteria, albeit some may not be explicit. In essence the competitive nature of lending will usually require a stretching, breach or 'view' to be taken on day one in order to win business. The hope is that the active asset management will rapidly and predictably restore the margins and add value-taking pressure off loan covenants.

\section{DOES ACTIVE MANAGEMENT REALLY EXIST?}

Active asset management does exist, but the degree of 'activity' has to be understood - it is an over-used phrase. It is important to understand what is meant in the particular circumstances that relate to any investment or fund. It may be an empty phrase, it may refer to a bit of gearing and the occasional rent review or it may apply to the full gamut of strategic activity that looks at enhancing property cashflows, values and returns.

\section{DOES ACTIVE MANAGEMENT ENHANCE RETURNS?}

Active asset management does enhance returns - but it is difficult to find objective data, since the definition of active asset management varies so much. Table 1 lists returns from some 
indices; it seems fair to suggest that all the parties who observers might consider to be undertaking some degree of active asset management show better returns.

Table I: Pooled property fund indices

\begin{tabular}{lcccc}
\hline $\begin{array}{l}\text { Results to end June } \mathbf{2 0 0 4} \\
\text { \% }\end{array}$ & $\mathbf{3}$ months & Ytd & $\mathbf{1 2}$ months & 3 years* \\
\hline NAV total return & & & & \\
All pooled funds index & 5.3 & 8.8 & 16.2 & 11.0 \\
All balanced funds index & 53 & 8.7 & 14.5 & 10.4 \\
Balanced property unit trust index & 4.9 & 8.5 & 14.4 & 10.3 \\
Managed property funds index & 5.8 & 9.0 & 14.6 & 10.6 \\
Total return & & & & 10.1 \\
FTSE real estate index & 5.0 & 15.6 & 418 & -3.5 \\
FTSE all-share index & 2.2 & 2.8 & 16.9 & 5.5 \\
FTSE 5-15-yr gilt index & -1.3 & 0.1 & -1.5 & \\
\hline
\end{tabular}

Source: IPD

*Annualised

\section{WHERE IS PROPERTY'S RETAIL MARKET GOING?}

Consultant Colliers CRE's recently reported prediction for retail property is not optimistic: it would be a poorer performer in 2005 with a total return of 12.5 per cent; high-street-specific retail will come in even lower, at 11.5 per cent; and this would lag behind offices at 13.5 per cent and industrial at 16.9 per cent. ${ }^{1}$ The overall predicted rental retail figure according to Colliers CRE is 6.2 per cent. The comparative paucity of these figures reflects low rental growth and the impact of earlier yield compression which cannot continue. In other words, just following the market in this sector will not be enough for the mean-beating appetites of most investors.

Yet according to 2005 research by consultant CB Richard Ellis

Retail property has outperformed the property market as a whole for the past three years
(CBRE) ${ }^{2}$ retail property has outperformed the property market as a whole for the past three years and is expected to show the highest returns again by December 2005 - although by a narrower margin over the other sectors compared to 2004 as returns ease back to the mid-teens. Looking further ahead, the firm expects returns to moderate further - potentially quite sharply - as the retail sector feels the effects of the slowdown in household spending and a weaker housing market.

With lower sales volume growth and a tougher climate for retailers generally, the retail sector is expected to see reducing rental momentum during at least the next couple of years, affecting both in-town and out-of-town shopping. Growth in high-street shop rental values has averaged only 1.7 per cent on the IPD Index during the past three years, although growth outside central London has been somewhat higher. In-town shopping centres have managed 3.5 per cent per annum rental growth during the past three years, while retail warehouses have seen stronger growth at 6.0 per cent per annum. 
For the three years to the end of 2007, CBRE's current forecasts ${ }^{3}$ show high-street shop rental growth slowing to 1.5 per cent per annum, with 2.2 per cent per annum average growth for in-town shopping centres and 4.4 per cent growth for the retail warehouse sector.

Pricing of property investments is currently being driven predominantly by the weight of money in the market. Property's recent performance has a strong story to tell investors disillusioned with global equity markets. With shares viewed less favourably in 2000-2002, property benefited from exceptional liquidity stimulated by low real interest rates in the world economy, reflected in the US ten-year bond rate of around 4 per cent.

In the near term, the factors supporting strong investor demand for UK property look likely to persist, comments CBRE. ${ }^{4}$ Further ahead, however, the same pressure of demand cannot be guaranteed. In particular, CBRE is uncertain how stable and sustainable the strong flows of money recently coming from personal investors and smaller pension funds into managed and pooled property funds will prove.

The timing and extent of any yield adjustment in the medium term remain highly uncertain, but it must be considered possible that some combination of higher bond deals (led by the USA), reduced income growth expectations and a higher risk premium for property could have an effect.

Retail property yields could prove vulnerable to adjustment in the face of difficult trading conditions and poor rental growth in the shops sector, particularly in parts of the secondary retail market. A good asset manager will try to spot trends and react in a timely manner, making the most of opportunities that result from market movements.

\section{WHAT DOES ACTIVE ASSET MANAGEMENT DO FOR RISK PROFILES?}

While it is difficult to provide a scientific answer, the author suggests that active asset management generally lowers risk: while the activity implies changing the status quo - and is therefore inherently less predictable - it makes the investment less static and therefore able to respond to market conditions.

\section{WHAT ARE THE RIGHT PROFIT MEASURES?}

Investors focus on internal rate of return (IRR), but this may not be comparing apples with apples. How does one weight returns for factors such as risk aversion, long-term perspective, paid-out income or capital return? Accordingly, it is spurious to analyse data and draw oversimplified and potentially dangerous conclusions.

The risk-reward analysis seems at first to be valid, but difficult to deal with in a non-subjective manner. Comparison of alternative 
The realities of active asset management assets or routes of investment also gives a guide. Target measures may be set, but they usually are set in terms of what is available and can at times prevent one entering a market.

\section{REALITIES AND PRACTICALITIES}

This section attempts to address the realities of active management - it is often vaunted, but do people really understand what it is and how it affects them as lender or investor? In simple terms there is already an early truth 'staring one in the eye' in the word 'active' - surely there is a tautology lurking in the undergrowth? If management is not active then it must by implication be 'passive' - and therefore not management at all but stock picking, something that is unlikely to do more than offer a market-based return.

It is difficult to be comprehensive on this matter: to have a full understanding of 'active asset management' it is useful to focus on the activities of overseas investors, many of whom originate from Ireland and started investing in the UK commercial property sector in the mid-1990s. These astute people - most of them private individuals, since employees of institutions were unwilling at the time to step up to the plate - bought billions of pounds of UK property investment stock, most of it on comparatively long leases - 12 or 15 years - with good tenant covenants. Gearing was mainly provided by Irish, Scottish and German banks, with local lenders far from shy. Gearing was usually quite high, with 80 per cent a good benchmark.

Often these overseas investors were invited to these shores by niche players and the main herd of investment agencies, many of whom promised 'active management' of the portfolios. During the next few years their investments produced fabulous returns - but the author suggests that very little of the returns were the product of genuine active management. In fact one would go so far as to say that the comparative yields (around 7.5 per cent in the UK, compared to Ireland's 5 per cent) and lower stamp duty rates were the main criteria of attraction.

The returns were generated by the fortuitous and coincidental impact of the combination of falling yields, reducing borrowing rates, high gearing and rental increases. The resultant returns on capital employed were florid, and made even more so by aggressive regearing and ratcheting of the original investment buying new stock on the back of revaluation of earlier purchases. There was little consideration of the relationship between equity and total geared investment. One suspects that many of the investment managers involved in this feast proclaimed themselves 'asset managers', many of them adopting the term 'active' as well. But in reality they did not have to be very active at all.

The economic situation has now changed, however: returns in commercial property will not be so spectacular without some form of enhancement. It is at this stage in the property cycle that the 


\section{Threats to UK economy highlighted}

\section{Slower rental growth}

reality of true active asset management will produce greater than market returns.

\section{THE UK'S CURRENT ECONOMIC BACKGROUND}

The speech that the governor of the Bank of England made at the end of 2004 - during his trip to Cornwall's Eden Project, a regeneration project that in itself reflects asset management, turning an ex-quarry into a world-renowned leisure destination (maybe it was 'development', with the distinction only being provided by a review of the degree of risk) - provided no glimmer of economic paradise, despite the UK's generally good health and promotion to fourth spot - from seventh - in AT Kearney's survey of the great and the good in terms of foreign direct investment (FDI). ${ }^{5}$

Rather than presenting a benign view of the 'rosiness' of the UK's garden the governor chose to warn that salary and consumer inflationary pressures still posed a threat in 2005. Investors in the FTSE took note, and the market fell.

Commentators prone to the view that interest rates would fall by Christmas had their hopes dashed, thanks principally to surveys that put average salaries in the private sector up by almost 5 per cent, with public sector salaries currently rising by about 4.25 per cent. Interest rates, according to commentators in July 2005, may well fall in August or September 2005. This reduction may ease pressure on many investors who have relied for the last few years on the differential in borrowing rates and property income.

\section{RENTAL GROWTH}

Rental growth looks to be fairly subdued. Retail rents have slowed, and while there is scarce supply of retail warehouses this is a tight sub-sector of the market with comparatively few players. Retail rents generally correlate well with levels of consumer spending, and indicators suggest that this is slowing.

Rowan's own experience, within the property funds it manages, is a case in point: in summer 2005 it is letting retail properties that other tenants have vacated, and the market is alive, if somewhat subdued. Only active managers will spot and exploit opportunities offered by decent locations and properties, so performance does not need to be damaged by a quieter tenant-side market.

Better news for investors in UK offices during autumn 2004 emanated from the office occupational market, which has shown some signs of recovery. Yet this is limited - there appears to be a considerable overhang of space still on the market. A period of bottoming out has occurred, but the rate of growth for the next few years is unlikely to be spectacular against a background of cautious and modest service-led business growth.

The industrial sector similarly shows few signs of offering any drama in rental growth performance, with IPD indications of 
Definition of active asset management minimal growth during the next period. ${ }^{6}$ Yet purchase yields have advanced to unprecedented high levels.

When it does arise, the impact of rental growth on geared investments can be dramatic. Not only will this improve immediate income returns, but it is likely to have a positive impact on values as yields are driven down by investors factoring rental growth into their valuations of new purchases. The bottom line can therefore be expressed in the following way: unless investors are content to take the more modest returns reflected by these overriding economic background indicators, true active asset management really will have to be employed.

\section{ACTIVE ASSET MANAGEMENT - WHAT IS IT?}

One definition of active asset management runs as follows: 'The organisation and systems that drive property investment cashflows to add investor value.' The following are key elements:

— information systems

- landlord and tenant relationships

- latent value analysis

- planning

- day-to-day management

- debt and gearing management

- lease structuring

- stock picking

- risk analysis and management.

There is no magic. Everything must focus on the management and improvement of cashflow. This is the fundamental activity that drives investment. It is not the exercise of development skills or risk, but the use of the medium of buildings to provide a long-term income stream from the capital investment in landed assets - the latter being a physical capital item that offers environmental control and functions to occupiers.

\section{Information systems}

It is essential to have accurate, comprehensive and accessible data on all properties and occupiers. These allow accurate and efficient accounting, and the holding of comprehensive and easily accessible property details. Good management of service charges and rating is essential. Information technology (IT) also allows a fund to analyse and look more closely at the latent value, rather than be reactive to property events such as reviews and lease ends.

\section{Relationships}

Building relationships with tenants - who should be seen as customers or clients - is something that seemed to elude, to its substantial discredit, the property industry for many years. A number of focused companies, however, are putting specialised 


\section{Key elements of active asset management}

CRM at the core of their activity. One would put near the top of this list Brixton Estate - a quoted plc which works now only on industrial stock and has dedicated customer relations teams.

Leases, rather than tenants, have been the concept that investors have scrutinised; but the active asset manager will realise that, by having a relationship with the tenant, opportunities will arise to negotiate more landlord-beneficial leases. This does not only refer to length, but also things like removal of existing tenant breaks and insertion of landlord breaks, fixed minimum uplifts and the like.

It may seem odd that a tenant should concede - but business does not always have the same drivers as property. Often a shortterm need for concession to improve year-end figures or ease cashflow squeezes, or terms that allow a sub-letting, will be priorities above immediate or deferred cost. The active manager will have a relationship with the tenant that is not only at rent review and lease end.

\section{Latent value analysis}

This analysis involves understanding opportunities vis-à-vis the commodity and its existing and future values in changing local markets - or physical constraints that may be altered. Just one example might be the acceptance of a surrender of a shop lease when it permits a change of emphasis, say, from household goods to fashion.

\section{Planning and change of use}

Planning allows change of use; it is an active management tool that can provide higher returns without the new planning permissions being exercised. This could be the subject of a whole book in itself, and there is little room here; suffice to say that working on planning while a building is still occupied allows for better vacant possession value which improves lending covenants, adds hope value to sales, opens positions with existing tenants and makes the market aware of pre-let opportunities. It also reduces risk, since new possibilities come into play - so planning should not be something that should be considered allied only to the development but a means to expand investment returns.

\section{Day-to-day management}

Matters such as rent reviews, management of service charges, properly carried-out maintenance plans and the like are all vitally important. Build long-term, positive relationships with tenants and, in due course, there will be fewer breaks in the building's leases and less resistance to rental uplifts and the like.

All these factors lead to greater cashflow and returns. It is important that there is someone driving the process who has an incentive to maximise opportunities such as rent reviews, but also that there is someone who can visualise and engage schemes to improve properties such as moving retail tenants, adding markets to 
Dramatic effect of gearing common areas, improving signage and planned maintenance programmes. These matters take time; it is important that the asset manager has sufficient internal resources and that strong relationships exist with teams of professional advisers.

\section{Debt and gearing management}

As Figure 1 shows, gearing can affect returns dramatically but appears to operate in a purely linear way. The reality differs, in that the downside position is partly protected by the ability of active managers to ameliorate circumstances so they are not showing returns that reflect the movement of market values. They are usually incentivised to enhance returns, and will not be likely to be passive in seeing rewards implied by bonus performance eroded and will take early action to avoid this.

Property is an illiquid and complex investment medium; it is not easy to exit positions - often, asset management strategies will need many months (and, sometimes, years) to enact and mature.

The impact on paid-out cashflow also needs to be considered, as only modest gearing will be allowed after all charges and interest have been accounted for.

Many funds are unable to gain the advantages of gearing because of cash requirements. The active asset manager will be important in coordinating debt and reducing the risk implied by carefully analysing and negotiating all the detail of the loan documentation, particularly in relation to the financial covenants that need to be carefully adhered to and monitored.

Also in relation to managing margins, when dealing with hedging to ensure that the fund is flexible and safe from interest rate fluctuations sophisticated asset management proves valuable. For example, choosing a swap rather than a fixed rate provides a potentially saleable or portable commodity rather than a 'dead' instrument.

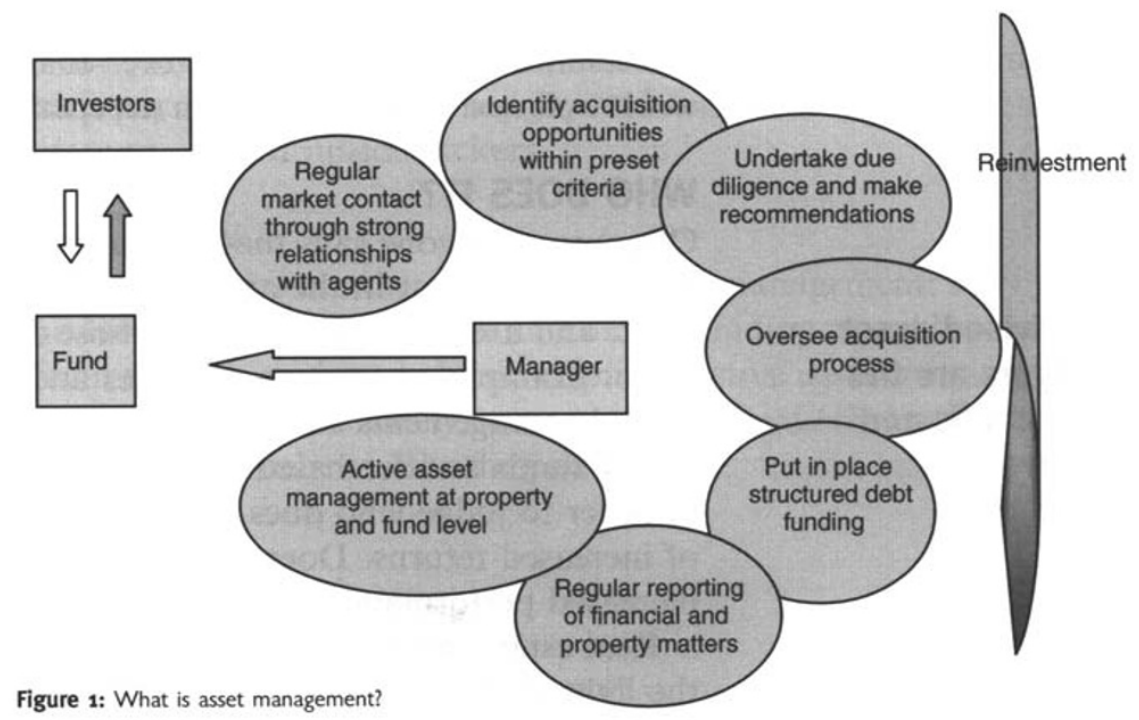




\section{Danger of over-gearing}

Gearing can also provide short-term liquidity, which enables an active manager to act quickly and effectively in a consistent manner in the market.

\section{Too much gearing?}

Of course it is possible to over-gear and, interestingly, careful cashflow exercises should be modelled to look at the variation of investor returns when mezzanine financing is employed. The marginal rates of mezzanine finance often reflect banks lending at points where their IRR target is in excess of the project IRR. It is worth asking the lender to indicate its target rate of return and compare it with that of the fund. Property players tend to be pragmatists and dislike missing deals; but they may need on occasion to find appropriately priced equity rather than borrowing at high margin mezzanine rates.

\section{Lease structuring}

Adjustment of lease terms can have a dramatic effect - but spotting the arbitrage between the positions of tenant and investor needs a vigilant and experienced eye. It also requires the ability to negotiate effectively and adroitly. Often it is useful to pose the question: 'What shape should my lease(s) be?'

\section{Stock picking}

The properly incentivised asset manager will spot and purchase the stock that not only has latent value but also has latent value that is likely to be realisable.

\section{Risk analysis and management}

Risk is taken in any transaction. Indeed, risk is even taken without a transaction as the passage of time changes circumstances - how many 1960s blocks of flats and offices now look like good longterm investments? Analysis of the level of risk sought is important. Yet it is more important to have asset managers who can understand and respond to the ever-changing world. The trick is to work well and profitably within acceptable parameters.

\section{WHO DOES IT?}

Of course everyone says they actively manage property, but one could suggest that in the ancient way of the world those who do it most, and are most effective, are those most incentivised to do so - for example, property companies and those working with highly geared arrangements such as commercial equity.

The funds and fee-based consultants have their place also. Again, in order to judge who does it, one should look at the implications of increased returns. Does the manager get increased returns from increased performance?

Real estate investment trusts (REITs) may do it if they ever see the light of day and are not neutered by legislation. Property 


\section{Active asset management should be applied irrespective of gearing levels}

companies do it most naturally — some better, some worse. Many do not realise they do it.

Consultants can do it, but the author is sceptical about the mindset. Motivation is crucial. Consultants are now hybrids: they have the passion and drive of property companies and the minds of logical and well-organised, sophisticated managers. They have realised that there is positive marriage of their skills to available deep pools of equity in such markets as collective investment.

\section{HOW DOES ACTIVE ASSET MANAGEMENT AFFECT RISK?}

Enhanced returns are sought, and these must imply a trade-off between risk taken and expectations of returns. There are degrees of risk implied, however, that may not be extreme. A well-managed agreement constrains the capacity of the asset manager to take on risk and gives him or her the freedom to avoid it.

\section{DOES ACTIVE MANAGEMENT RELY ON RISKY LEVELS OF GEARING?}

Gearing implies risk - and it seems that, almost without exception, active asset managers rarely seek gearing since they are returnfocused and believe in their own skills to manage the risk implied. But active asset management should be applied irrespective of gearing levels. It is entirely focused on achieving above-market performance returns.

\section{FEES}

Anything may be agreed; but suffice to say that the author recommends only those arrangements that lean heavily on performance-related returns and ensure a 'parallel interest' between investor and manager.

It is important to ensure that the manager is rewarded so that he or she has resources available to manage investments properly even if super rewards are not going to be available because of unforeseen market conditions.

All in all, the author recommends erring towards arrangements which pay for skills, ensure loyalty and focus and provide generous and, even, shared upside kickers.

\section{CONCLUSION}

The practicalities are the realities of active management: only those who have the resources, skills and understanding are able to take effective action and earn the description 'active asset manager'. They do not exist as widely or as uniformly and efficiently as the industry might believe. But they do enhance returns and can reduce risk.

\footnotetext{
References

1 Colliers CRE, see www.collierscre.com.

2. CB Rıchard Ellıs (CBRE), see www.cbre.co.uk.
} 
3. Ibld

4. Ibid.

5. AT Kearney, see www atkearney.com

6. Investment Property Databank (IPD), see www.ipdındex co.uk. 